\title{
On the Fractality of Young Athletes Training Process
}

\author{
Orlov A.I. \\ I.N. Ulyanov state University, Cheboksary \\ Cheboksary, Russia \\ san-04@rambler.ru
}

\author{
Kolesnikova O.B. \\ I.N. Ulyanov state University, Cheboksary \\ Cheboksary, Russia \\ olgkoles@rambler.ru
}

\author{
Schneider M.G. \\ I.N. Ulyanov state University, Cheboksary \\ Cheboksary, Russia \\ shnaydermarina1@mail.ru
}

\begin{abstract}
In the context of the fact that the traditionally organized training process of young athletes is approaching its functional limit, the need for new approaches to solving the problem of its activation is noted. Based on the four-level methodology of scientific analysis, which proves the justification for the use of I. Kant's teachings on a priori knowledge, the provisions of the psychological theory of activity on its multi-level structure and the results of research in the field of theory and methodology of professional education, the authors substantiate the fractal structure of young athletes training process. In relation to competitive activity, it is recommended to subdivide not only physical training into general and special, but also technical-tactical and psychological. It argues the importance of expanding the arsenal of sports training by means of the attention properties purposeful development determining the effectiveness of competitive actions.
\end{abstract}

Keywords-sportsmanship; young athletes; structure of the training process.

\section{INTRODUCTION}

Steadily increasing sports competition determines the search for new approaches to intensify the training process. Moreover, while in the sport of top achievements this problem has been successfully solved for many years by the Russian Olympians Support Fund [[7]], then with regard to the preparation of a sports reserve in modern conditions, the question remains open. While its solution will ensure the continuity of sports generations and strengthen the composition of national teams in future.

\section{LITERATURE REVIEW}

As the analysis of sports and pedagogical literature shows, in the theory and practice of sports training, a systematic approach was widely used [[8], [13], [17]]. The main provisions of it formed the basis of a number of thesis works conducted as before (Sh.K. Ageev, 1982 .; V.F. Grigoryan,
1982; V.P. Korkin, 1984; M.L. Kulikov, 1991; V.V Chesikhina, 1996 and others), and more recently (N.I. Shagin, 2017; A .N. Denisenko, 2018; V.M. Voronov, 2019, etc.) Based on the fact that, within the framework of this approach, the main system-forming factor is the result of the system functioning (P.K. Anokhin, 1978), specialists in sports training as the goal of the training process, as a distant image of the future result, consider the formation of sportsmanship, traditionally understood as a harmonious unity of all components of optimal competitive readiness - physical, technical, tactical and psychological [[20]]. With this view in mind, the three-component structure of the training process is generally accepted, its means are specified and methods for their implementation are developed. Moreover, regardless of the specifics and nature of competitive activity, physical training is historically divided into general and special. The first of it is the foundation for the development of the second [[1]]. In relation to issues of technical and tactical training, the opinions of researchers differ somewhat. There is a statement that technical and tactical trainings are separate aspects of the training process [[14], [15]]. Others [[5], [24], etc.] hold the opinion that technical and tactical trainings are a single process. Regarding psychological preparation (in its traditional sense), the opinions of researchers do not fundamentally differ. As a rule, when choosing its content and orientation, sports teachers take into account the characterological characteristics of athletes and their temperament, in accordance with which they select the means of various neuropsychiatric and pre-start states regulation, the development of moral-volitional qualities, the formation of a motive for competitive and training activities [[4], [6], [9], [18], [19]].

Despite of the fact that the structure of the training process under consideration with minor changes is generally accepted and has earned well-deserved recognition, it should be noted that the sports training of young athletes organized on its basis 
has almost reached its functional limit. It leads to the search for new approaches to its correction.

\section{RESEARCH METHODOLOGY}

As a methodological basis for the theoretical work, we took a four-level methodology of scientific analysis (I.V. Blauberg, E.G. Yudin 1973). It provides a consistent study of the problem at the philosophical, general scientific (systemic), specifically scientific and technological levels. Being in close interaction and mutual complementation, these levels allow not only to avoid posing the pseudo-scientific problems of the study, but also to verify its results from the truth point of view [[3]].

It is known that the main sources of any nature object development is a contradiction, in our case, between the existing level of sportsmanship and the desired one. At the same time, in accordance with the ideas of dialectical materialism, true development is determined by the ratio of such philosophical categories as "form" and "content". The extrapolation of the sports training practice determines the need for more detailed detailing of young athletes sportsmanship structure, which, in turn, will make it possible to actualize additional means of its development and, accordingly, expand the arsenal of means of their sports training.

In view of this and in the context of the fact that the traditional approach to organizing the training process of young athletes has approached its functional limit, it seems logical to take into account the teaching of I. Kant on methods for obtaining a priori knowledge. In accordance with which, when it is impossible to obtain new knowledge about the studied object in the framework of traditional concepts, one should go beyond their boundaries [22]. In relation to the study, this means the importance of finding the theoretical base that would contain the ability to obtain new knowledge about ways to activate the training process. In this regard, the results of studies conducted in the field of theory and methodology of professional education, which can be interpreted in two aspects, are of interest.

The first aspect is manifested in the fact that both vocational training and sports training are focused on preparing the subject of activity for its implementation. It should be noted that the main vector of the vocational training development is considered the competency-based approach (O.G. Rogovaya, 2007; S.I. Gilmanshina, 2008; T.A. Matveeva, 2008; A.A. Temerbekova, 2009; A.V. Tutolmin, 2009; L.L. Balakina, 2010). The justification for its application in our research can be determined by the fact that sportsmanship is nothing more than a specific kind of competence. Accordingly, the provisions of this approach can be applied in the analysis of young athletes sportsmanship formation problems and, in our opinion, can resolve the differences on the essence of athletes technical and tactical training. For what, it makes sense to pay attention to the operational-technical unit of a person's professional development model [[11]]. Adapting it to the practice of sports training, it becomes possible to trace the dynamics of young athletes sports skills (competence) development.
According to I.N. Moshkova and S.L. Malova (1990) the activity (including sports and competition) can be carried out at three levels of difficulty. At the same time, the minimal level is the activity of the "operator", a characteristic feature of which is its direct execution by the subject of activity with the purpose of the activity set out from the outside and the means of its implementation. A more complex activity is the activity of the "planner", the main task of which is the choice of carrying out activities means for the purpose formulated by someone. The activity of a "designer" is recognized as the most complex. It autonomously determines the purpose of the activity and chooses the means of its implementation.

Along with the listed complexity levels of the activities' implementation, in accordance with the ideas of R. Dilts (2001) and N.A. Kozlova (2002), in its development, it goes through several evolutionary stages. It starts its complication from unconscious incompetence to conscious incompetence, and then through conscious competence up to unconscious competence. At the first stage of the competence development, the subject of activity does not yet realize his failure (incompetence). It is often found among sportsmen-beginners who, observing the apparent ease of performing technical actions by experienced athletes, mistakenly assure themselves of their abilities. And only as a result of a trial-and-error series in the performance of the learned actions, the subject of activity proceeds to the next stage - conscious incompetence. Further, as the mastery of the execution technique is mastered, the young athlete moves to the level of conscious competence when the performed actions are consciously controlled by the subject of activity. In the framework of the theory and methodology of physical education, this stage of competence development is related to the level of motor skill. Therefore, the next stage in the competence development corresponds to the level of motor skill, when actions are performed automatically.

If the above levels of activity by I.N. Moshkova and S.L. Malov we reflect on the abscissa axis. On the ordinate axis we reflect the stages of competence development by $\mathrm{R}$. Dilts and N.A. Kozlov. Then it becomes possible to trace the evolutionary development of sportsmanship. Starting from the stage of unconscious competence at the level of activities performance, developing towards unconscious competence at this level, which creates the conditions for the transition to its complexity at the level of planning activities, also starting from the stage of unconscious competence and similarly going through its evolutionary stages.

The resulting coordinate system allows not only to trace the dynamics of the formed competence development in competitive activity, but also specifies the means and sequence of their implementation in the development of sportsmanship. In addition, it gives us reason to say that both technical training, as the ability to perform competitive actions most rationally, and tactical training, as the ability to choose the method and sequence of performing technical actions depending on the current competitive situation, represent a single type of preparation for competitive activities. At the same time, the understanding that the increased motor equipment of young athletes creates favorable conditions for expanding their technical arsenal, allows us to subdivide the 
technical and tactical trainings of young athletes into general and special.

The second aspect of the research results appropriation from the field of professional education into the practice of sports training is seen in the fact that they allow you to identify additional means of the training process. It is generally recognized that in preparing for professional activities, often carried out under specific conditions, professionally applied physical training is essential. Moreover, depending on the increasing intellectualization of production and its knowledge-intensiveness, the emphasis of research in this area is shifting from the development of applied motorphysical qualities and the formation of the body's resistance to adverse production factors (I.V. Dimanskas, 1967; Yu.P. Bobylev, 1974; V.I. Ilinich, 1978; D.A. Valeev, 1979; S.A. Polievsky, 1980; B.I. Zagorsky, 1981; V.A. Kabachkov, 1982; E.P. Guk, 1983; A.I. Garalis, 1983; R.T. Raevsky, 1985; M.Ya. Vilensky, 1996 and many others), towards the formation of professionally important psychophysical functions (N.A. Alyoshev, 2007; E.A. Zyurin 2008; M.G. Schneider, 2009; O.N. Sergeeva, 2012, etc.). Based on the position of the psychological theory of activity (A.N. Leontyev, L.S. Vygotsky, S.L. Rubinstein, Yu.B. Gippenreiter, etc.) about its multi-level organization (regardless of the activity complexity, its effectiveness is to a certain extent determined by the formation of psychophysical functions the authors developed a set of means for developing the properties of attention. They are primary in relation to thinking and, accordingly, determine its quality [[16]]. Indeed, it is impossible to imagine an air traffic controller or a hightech production operator, who is forced to keep in mind simultaneously many of the process parameters displayed on electronic displays without the necessary attention properties that facilitate the prompt adoption of certain decisions depending on the situation. By analogy with the aforesaid, the training process of young athletes should also contain the means aimed at the formation of certain properties of attention that determine the effectiveness of competitive activity. This can be confirmed by the results of studies [[12]]. According to them, over the years of training, athletes specializing in sports with a predominantly subject-object nature of competitive activity developed a greater concentration of attention. While representatives of situational sports characterized by a predominance of subject-subject interactions when performing competitive actions, the indicators of switching and distribution of attention are most improved. However, it should be noted that these changes occur indirectly. While we insist on the need for their targeted development in the process of preparing for competitions. In the logic of this thesis, the division of psychological preparation in relation to competitive activity into general and special is seen as natural. The first should be focused on the athletes motivationalvolitional sphere formation and the development of the ability to regulate pre-launch conditions. All of them are essential for all athletes regardless of the chosen sport; the second should be focused on the purposeful development of the properties of certain attention properties that determine the effectiveness of competitive activities.

\section{IV.RESULTS}

Summarizing the above, it can be stated that the fractal theory of B. Mandelbrot [[10]], which has recently become widespread in the natural sciences and humanitarian disciplines and involves the consideration of the studied objects in the form of a single set of self-similar elements, can be taken into account when analyzing the problems of sports training. According to the author of this theory, if one element of a set has a certain structure, then its other components are similar in structure [[10]], and behind the seeming chaos of nature, developing according to fractal laws, there is an order that must be seen [21]. In addition, the conducted theoretical study not only correlates with the principle of competitive activity primacy in relation to training [[13]], which obliges sports educators to take into account the specific conditions of competitive activity when choosing the content of the training process, but also more fully disclose it.

The practical significance of the study indicating the fractal structure of young athletes training process is that, firstly, its results allow us to determine additional means of sports training, thereby reducing the entropy potential of the training process, understanding it as a specially built pedagogical system. At the same time, it is expected that the revealed means of special psychological preparation, in conjunction with those traditionally implemented in all components of the training process, will give a significant synergistic effect.

Secondly, the revealed fractal structure of the training process can serve as the basis for developing a model of young athletes competitive readiness. In which the normative and descriptive levels of readiness would be correlated according to the indicators of the general and special physical, technical, tactical and psychological components. They would ensure an increase in the manageability of the training process by means of a targeted effect on the lagging sides of competitive readiness. Using the categories of systems general theory, in accordance with the chosen research methodology, which is a specification of the provisions of the diamate, the proposed model will create conditions for determining the limiting factor constraining the functioning and development of the system (T.B. Robertson, 1923; A.A. Bogdanov, 1925), in our case, sportsmanship system.

\section{CONCLUSIONS}

Summing up the above, we can formulate a number of particular conclusions:

1. Increasing the efficiency of young athletes training process in modern conditions, characterized by the achievement of the traditional approach functional limit to its organization, is possible on the basis of scientific analysis four-level methodology. The justification for its application is determined by the fact that it defines worldview approaches and a set of scientific disciplines as a tool for understanding the problem being studied, thereby determining the search vector for the answer to the question through which 
[3] Great Soviet Encyclopedia. 3rd ed. M. 2008, 2944.

[4] Glushkova, S.Yu. Theories of swimming. URL: https://educontest.net/ru/1425065/

[5] Dudkin, V.V. Technical and tactical preparation of the execution of throws in sambo. Samara: Publishing house of Samara University. 2017, 64.

[6] Zagainov, R.M. Psychological skill of a trainer and an athlete: a toolkit for Olympians. M.: Soviet Sport. 2005, 106.

[7] Meeting of the Council for the Development of Physical Culture and Sports. URL: http://www.kremlin.ru/events/president/news/60152

[8] Kuznetsov, A.S. Organizational and methodological foundations of long-term training of Greco-Roman style wrestlers. Pedagogicopshycological and medico-biological problems of physical culture and spot. 2016, vol. 11(1), pp. 47-56. DOI: 10.14526/01_1111_78

[9] Kuznetsov, A.S., Zakirov D.R., Krikukha Yu.Yu. Individualization of training of Greco-Roman style wrestlers by different types of temperament. Pedagogico-pshycological and medico-biological problems of physical culture and spot. 2013, vol. 8(2), pp. 68-79.

[10] Mandelbrot B. Fractal geometry of nature. M.: Institute for Computer Research. 2002, 656.

[11] Markiyanov, O.A., Kosheleva, N.V., Orlov, A.I. The social space of a personality professional development: monograph. Cheboksary. 2006, 188.

[12] Markiyanov, O.A., Orlov, A.I., Oreshkina, T.I. The development of the properties of mental processes as a component of the psychological preparation of an athlete. Bulletin of sports science. 2009, no. 2, pp. 811.

[13] Novikov, A.A. Fundamentals of sportsmanship. M.: Soviet Sport. 2012, 254.

[14] Pashchenko, A.Yu. Technical and tactical training of football players: educational-methodical manual. Nizhnevartovsk: Publishing house of Nizhnevartovsk State University. 2016, 142.

[15] Pismensky, I.A. Physical education. URL: https://studme.org/1584072029457/meditsina/fizicheskaya_kultura

[16] Rudik, P.A. Psychology: textbook for physical culture institutes. M.: FiS. 1974, 511.

[17] Pyanzin, A.I. Sports training of track and field athletes. M.: Theory and practice of physical culture. 2004, 369.

[18] Rakhmatov, A.A. The individuality of skill in team sports. Pedagogy today: problems and solutions: materials of the III Intern. scientific conf. (Kazan, March 2018). Kazan: Young Scientist. 2018, pp. 49-51. URL: https://moluch.ru/conf/ped/archive/276/13810/

[19] Saveliev, D.S., Murasheva, M.V., Levitsky, A.G., Matveev, D.A. Augmented mental training in the training system for beginner sambo wrestlers. TPFK. 2014, no. 2. URL: http://www.teoriya.ru/ru/node/1363

[20] Terzi, M.S., Saraikin, D.A., Pavlova, V.I., Kamskova, Yu.G. Psychophysiological determinants of martial arts sportsmanship. TPFK. 2014, no. 12, pp. 66-71.

[21] Three books on fractals // https://mustread.livejournal.com/15128.html

[22] Trufanov, S.N. On the main provisions of the "Critique of Pure Reason by I. Kant”. URL: / http:// lit.libru/t/trufanow_s_n/text_0060.shtml

[23] Zinker, V.M. Physiological and methodological foundations of the development of motor qualities of athletes: textbook. Ulan-Ude: Publishing House of BSU. 2011, 216. 